\title{
A CERTIDÃO NEGATIVA DE DÉBITO E A DECISÃO DE PAGAR TRIBUTOS
}

\author{
Nelson Leitão Paes \\ Universidade Federal de Pernambuco (UFPE)
}

\section{A CERTIDÃO NEGATIVA DE DÉBITO E A DECISÃO DE PAGAR TRIBUTOS}

Resumo: 0 artigo expõe que, para atender a previsão de exigência de regularidade fiscal do artigo 205 do Código Tributário Nacional, foi criada a Certidão Negativa de Débito (CND). Aponta que a CND é condição necessária para as firmas participarem do sistema de compras governamentais e representa um estímulo para as firmas manterem as suas obrigações tributárias razoavelmente em ordem. Para avaliação dos efeitos deste mecanismo sobre 0 cumprimento da obrigação tributária, constrói um modelo simples de equilíbrio parcial, verificando que, quanto mais tributado for o setor e/ou menor for a exposição do seu faturamento ao setor público, menores serão as exigências do governo para concessão da CND. Com base na solução do modelo e em dados das contas nacionais de 2006, identifica os setores em que o governo deveria ser mais exigente na emissão da certidão, como os serviços às empresas, construção, produtos farmacêuticos e serviços de informação. Constata, por fim, que os setores menos afetados pela CND são as empresas de eletrodomésticos, fumo, mineração e metalurgia.

Palavras-chave: Evasão fiscal, CND, comportamento da firma.

\section{NEGATIVE DEBT CERTIFICATE AND THE DECISION TO PAY TAXES}

Abstract: The article exposes that, to attend the prevision of demand of tax regularity from the article 205 of the National tributary Code was created the Negative Debt Certificate (CND in Portuguese).Points out that CND is a necessary condition to firms participate of the government shopping system and represents an incentive to firms maintain their tributary duties reasonably in order. In order to evaluate the effects of this mechanism about the fulfilment of tax obligation, it was constructed a simple partial equilibrium model, understanding that, the higher is the tax rate to the sector and/or the lower is the exposure of its revenues to the public sector, the smaller the governments requirements for granting CND will be. Based on the solution of the model with the aid of Brazilian national accounts of 2006, identifies sectors where the government should be more rigid to give the CND, like services to firms, construction, pharmaceutical products and information services. Finally, it notes that, the sectors less affected by CND are appliances companies, cigarettes producers, mining and metallurgy.

Keywords: Tax evasion, CND, firm behavior. 


\section{INTRODUÇÃO}

Prevista no artigo 205 do Código Tributário Nacional, a Certidão Negativa de Débito (CND) obtida junto à Secretaria da Receita Federal do Brasil (RFB) assegura, salvo prova em contrário, que o contribuinte está em dia com as suas obrigações tributárias. A certidão é necessária para uma série de atos empresariais, como alienação de bens imóveis, baixa de empresas, operações de empréstimos junto a fontes oficiais, e o mais importante para as firmas, se habilitar a participar em processos licitatórios para oferecer bens e serviços à Administração Pública. Somente com a CND é possivel vender bens e serviços para os governos.

Dado o peso do setor público na economia, tal restrição nas compras governamentais representa um estímulo para as firmas manterem as suas obrigações tributárias razoavelmente em ordem. Trata-se, portanto, de poderoso instrumento para as Administrações Tributárias, no esforço de convencer os contribuintes a regularizar a sua situação tributária. Entretanto, o uso da CND neste contexto tem sido contestado, pois muitos contribuintes veem a certidão como um mecanismo coercitivo burocrático e indevido.

A questão que se coloca neste trabalho é qual a rigidez que se deve exigir no pagamento dos tributos para a confecção da CND. Conjectura-se que caso o governo adote uma postura muito flexível na concessão ou, por outro lado, seja muito rígido, pode tornar o instrumento inoperante. Por exemplo, se for concedida a CND para firmas que costumam pagar apenas $1 \%$ dos tributos devidos, a certidão perde o sentido na sua finalidade. De outra forma, caso ela seja fornecida somente para aqueles que pagam $99 \%$ das suas obrigações tributárias, 0 universo de interessados em vender para a administração pública pode se tornar muito reduzido. Cabe lembrar o tamanho da carga tributária brasileira, bem como a complexa legislação e as inúmeras obrigações acessórias que dificultam o cumprimento integral da obrigação tributária principal.
0 artigo procura determinar qual o nível máximo de cumprimento na obrigação de pagar tributos o governo poderia aceitar na concessão da CND. Verificou-se que quanto mais tributado é o setor, menor a exigência do setor público, e quanto maior o peso das compras governamentais, mais exigente é a administração pública. Este cálculo é feito de forma setorial, usando dados das Contas Nacionais do Instituto Brasileiro de Geografia e Estatística (IBGE).

O trabalho está dividido em cinco partes, com esta introdução, e mais a seção seguinte que trata de uma breve descrição do instrumento Certidão Negativa de Débito. $\mathrm{Na}$ terceira seção o modelo é descrito, enquanto que na quarta se apresentam os resultados obtidos e na quinta as principais conclusões.

\section{A CERTIDÃO NEGATIVA DE DÉBITO}

A exigência de regularidade fiscal está prevista no artigo 205 do Código Tributário Nacional (CTN), que dispõe que

A lei poderá exigir que a prova da quitação de determinado tributo, quando exigivel, seja feita por certidão negativa, expedida à vista de requerimento do interessado, que contenha todas as informações necessárias à identificação de sua pessoa, domicílio fiscal e ramo de negócio ou atividade e indique 0 período a que se refere o pedido. (BRASIL, 1966).

Em complemento, seu parágrafo único dispõe que

\begin{abstract}
A certidão negativa será sempre expedida nos termos em que tenha sido requerida e será fornecida dentro de 10 dias da data da entrada do requerimento na repartição. (BRASIL, 1966).
\end{abstract}

Os artigos 151, 156 e 206 do CTN também autorizam a emissão da CND nos casos em que os débitos tributários estejam quitados, parcelados, prescritos, depositados judicialmente, suspenso por liminar ou em discussão administrativa. A exigência é justificável já que permite ao Fisco diferenciar os contribuintes e direcionar as compras públicas para aqueles que cumprem com suas 
obrigações tributárias. A CND é válida por 180 dias.

A CND é condição necessária para uma série de atos dos contribuintes, como por exemplo:

- Participação em licitação pública (Lei $n^{0} 8.212$, de 24 de julho de 1991 e Lei $n^{0} 8.666$, de 21 de junho de 1993);

- Alienação ou oneração de bem ou direito relativo a imóvel (Lei $n^{0} 7.711$, de 22 de dezembro de 1988 e Lei $n^{0}$ 8.212/1991);

- para o registro ou arquivamento de ato relativo à baixa ou redução de capital de firma individual, para redução de capital social, cisão total ou parcial, transformação ou extinção de entidade ou sociedade comercial ou civil e transferência de controle de cotas de sociedades de responsabilidade limitada (Lei $\mathrm{n}^{0}$ 8.212/1991);

- Para o reconhecimento de benefício ou incentivo fiscal (Lei n⿳0 9.069, de 29 de junho de 1995);

- Concessão de concordata e declaração de extinção das obrigações do falido (Decreto-lei $n^{0}$ 1.715, de 22 de novembro de 1979);

- Transferência de residência para o exterior (Decreto-lei no 1.715/1979 e Lei $n^{\circ}$. 7.711/1988).

Entretanto, a CND é alvo de pesadas críticas por parte das firmas brasileiras, que veem neste instrumento um grande entrave burocrático e sujeito inclusive a erros cometidos dentro do próprio Ministério da Fazenda. Reclama-se da exigência de formulários, extratos, cópias e outras documentações que atravancam e atrasam o processo de emissão da certidão. Segundo pesquisa da PricewaterhouseCoopers (2006), 92,6\% das 117 empresas pesquisadas pela consultoria já deixaram de concluir negócios pela demora na obtenção da CND.

Neste artigo o foco não será as dificuldades das firmas em obter a certidão, e sim 0 seu caráter incentivador para 0 cumprimento da obrigação tributária. Assim, na próxima seção apresenta-se o modelo para o estudo do efeito da CND sobre o pagamento de tributos por parte das firmas.

\section{MODELO}

Neste modelo, a firma ao maximizar seus lucros escolherá se seria mais vantajoso cumprir um percentual mínimo da sua obrigação tributária e ter acesso às compras governamentais ou se seria melhor não pagar tributos e se manter longe do setor público. Por hipótese, as firmas não são competitivas e resolvem o mesmo problema de maximização de lucros, escolhendo capital e trabalho que maximizem a equação (1) abaixo:

$\max$

$$
\pi_{i}=\left(1-\alpha_{i} \tau_{i}\right) k_{i}^{y} h_{i}^{\theta}-w h_{i}-r k_{i}-p\left(1-\alpha_{i}\right) \tau_{i} k_{i}^{y} h_{i}^{\theta}
$$

Onde $\alpha_{i}$ é a fração do imposto devido, $\tau_{i} k_{i}^{\gamma} h_{i}^{\theta}$, que será pago pela firma $i$. Como usualmente definido, $y_{i}$ é o produto da firma $i$, $w$ é o salário, $h_{i}$ são as horas trabalhadas na firma $i, r$ é a taxa de mercado de retorno do capital e $k_{i}$ é o estoque de capital da firma i. 0 parâmetro $\gamma$ refere-se à participação da renda do capital no produto e $\theta$ é a participação da renda do trabalho no produto. 0 parâmetro $p$ representa não só a probabilidade de que o contribuinte seja auditado pelas autoridades fazendárias como também representa as multas aplicadas ${ }^{1}$. Assim, o último termo da equação (1) representa o valor esperado a ser lançado administrativamente de ofício em função de que partes do tributo devido não foram pagas, caso em que $\alpha_{i}<1$.

É interessante realçar que esta abordagem microeconômica é utilizada pela literatura que trata de evasão fiscal. São exemplos o artigo de Siqueira e Ramos (2006) que estuda a decisão de indivíduos de pagar tributos sob a ótica da utilidade esperada, aprofundando 0 artigo de Allingham e Sandmo (1972), enquanto que Arante (2006) usa a teoria do principal agente para estudar a possível reação das firmas, em relação à decisão de evasão fiscal, às propostas de 
reforma tributária. Marreli (1984) e Yaniv (1995) introduzem a decisão de produção das firmas em um modelo similar ao de Allingham e Sandmo (1972) num ambiente onde a sonegação é possível. $O$ que há de inovação no presente artigo, ainda não analisada pela literatura que trata do tema, é a inclusão da Certidão Negativa de Débito como instrumento de restrição e geração de lucros da firma, e como este instrumento afeta a decisão da firma de pagar tributos.

As condições de primeira ordem, após alguma manipulação algébrica, nos fornecem as equações (2) e (3) a seguir:

$$
\begin{aligned}
& r=\left[\left(1-\alpha_{i} \tau_{i}\right)-p\left(1-\alpha_{i}\right) \tau_{i}\right] \gamma k_{i}^{\gamma-1} h_{i}^{\theta} \\
& w=\left[\left(1-\alpha_{i} \tau_{i}\right)-p\left(1-\alpha_{i}\right) \tau_{i}\right] \theta k_{i}^{\gamma} h_{i}^{\theta-1}
\end{aligned}
$$

Substituindo (2) e (3) em (1) obtemos:

$\pi_{i}=(1-\theta-\gamma)\left[\left(1-\alpha_{i} \tau_{i}\right)-p\left(1-\alpha_{i}\right) \tau_{i}\right] k_{i}^{\gamma} h_{i}^{\theta}$

$$
\text { Derivando (4) em relação a } \alpha_{i} \text {, }
$$

obtemos:

$$
\frac{\partial \pi_{i}}{\partial \alpha_{i}}=(1-\theta-\gamma) k_{i}^{\gamma} h_{i}^{\theta}(p-1) \tau_{i}
$$

Percebe-se que 0 aumento do percentual de cumprimento da obrigação tributária reduz os lucros, $\frac{\partial \pi_{i}}{\partial \alpha_{i}} \leq 0$, já que por definição $p \leq 0$.

Suponha que o governo estabeleça um percentual mínimo $\bar{\alpha}_{i}$ específico por setor para emissão da CND e, consequentemente, para a firma ter acesso às compras do Estado. A adoção do percentual mínimo neste modelo tenta representar o fato de que para a emissão da CND a avaliação da situação fiscal da firma é sumária, ou seja, de forma a dar mais celeridade ao processo de emissão sacrifica-se a acurácia no exame. Assim, a firma pode escolher pagar menos do que o determinado pelo governo e não vender para a administração pública, ou pagar um percentual maior ou igual ao mínimo e vender para o setor público.

Por outro lado, como os lucros são decrescentes com o percentual de pagamento do imposto, a firma escolherá entre duas opções - ou não pagar nada e não vender para - governo ou pagar o percentual mínimo estabelecido e vender. Para o primeiro caso escolheu-se o sobrescrito $L$ e para o segundo caso o sobrescrito $H$. Assim, as duas possibilidades de lucro são:

$$
\pi_{i}^{L}=(1-\theta-\gamma)\left(1-p \tau_{i}\right) c_{i}
$$

$\pi_{i}^{H}=(1-\theta-\gamma)\left[\left(1-\bar{\alpha}_{i} \tau_{i}\right)-p\left(1-\bar{\alpha}_{i}\right) \tau_{i}\right]\left(c_{i}+g_{i}\right) \quad(7)$

Observe que se considerou que no caso $L$ o produto, $k_{i}^{\gamma} h_{i}^{\theta}$, é igual somente ao consumo privado do bem produzido pela firma $i$, enquanto que no caso $H$, o produto é igual a soma do consumo privado e público do bem produzido pela firma $i$.

\section{RESULTADOS}

Igualando os lucros das equações (6) e (7) encontramos qual seria o percentual de cumprimento da obrigação tributária fixado pelo governo que faria com que as firmas escolhessem pagar em tributos, ou seja, ser do tipo $H$ e não $L$ :

$$
\bar{\alpha}_{i}=\frac{\left(1-p \tau_{i}\right) g_{i}}{\tau_{i}(1-p)\left(c_{i}+g_{i}\right)}
$$

Caso o governo escolha qualquer percentual abaixo do calculado acima, as firmas neste setor prefeririam pagar tributos $e$ obter a CND. Com percentuais acima, elas escolherão não pagar tributos e ficar sem a certidão.

Derivando $\bar{\alpha}_{i}$ em relação a $\tau_{i}$ e em relação a $g_{i}$, temos que:

$$
\frac{\partial \bar{\alpha}_{i}}{\partial \tau_{i}}=-\frac{g_{i}}{\tau_{i}^{2}(1-p)\left(c_{i}+g_{i}\right)}
$$




$$
\frac{\partial \bar{\alpha}_{i}}{\partial g_{i}}=\frac{\left(1-p \tau_{i}\right)}{\tau_{i}(1-p)\left(c_{i}+g_{i}\right)} \cdot \frac{c_{i}}{c_{i}+g_{i}}
$$

Observa-se que quanto maior a tributação no setor, mais flexível deve ser 0 governg nas exigências para a concessão da CND, $\frac{\partial \alpha_{i}}{20}$, e por outro lado, quanto mais dependêtrte das compras da administração pública for o setor, mais rígida deve ser a cobrança pelo cumprimento da obrigação tributária para a emissão da certidão, $\frac{\partial \alpha_{i}}{\partial \rho}>0$. Em relação às compras do governo a $\partial$ inculação entre a maior exigência da CND para os setores mais dependentes do governo é clara. Mais complexa é a relação com a tributação. Para alíquotas mais altas, o governo torna-se mais flexível porque a tributação mais elevada reduz o lucro das firmas e se 0 governo pretende que as firmas escolham ser do tipo $H$ e não do $L$, que não pagam tributos, então é obrigado a aceitar emitir a CND com menores exigências.

Nesse sentido, $\bar{\alpha}_{i}$ elevado significa que são setores mais dependentes das compras governamentais ou menos tributados, e que obtém lucros razoáveis mesmo com um governo mais vigilante na emissão da certidão. Se o governo for mais leniente para este grupo, abrirá mão de recursos tributários de firmas com plena capacidade contributiva.

Podemos usar os dados das contas nacionais de 2006 (INSTITUTO BRASILEIRO DE GEOGRAFIA E ESTATÍSTICA, 2008) para uma estimativa do quão rígido deve ser 0 governo para concessão da CND nos diversos setores da economia. A tabela no apêndice apresenta os dados setoriais. Quanto ao parâmetro $p$, que indica a probabilidade de auditoria multiplicada pela multa aplicada, dados da RFB mostram um valor lançado de cerca de $\mathrm{R} \$ 55$ bilhões em $2006^{2}$ para uma arrecadação de $\mathrm{R} \$ 372$ bilhões (BRASIL, 2007), de forma que escolhemos $p=15 \%$.

Com os dados do anexo, substituindo na equação (7), podemos calcular o valor de $\bar{\alpha}_{i}$ para cada setor econômico das contas nacionais. A Tabela 1 a seguir apresenta os resultados.

Os setores foram classificados como de risco mais alto aqueles cujo percentual foi superior a $70 \%$, de risco médio aqueles com percentual entre $30 \%$ e $70 \%$ e os de baixo risco os de percentual inferior a $30 \%$.

Os setores de risco médio e alto merecem maior atenção do governo na concessão das CND. São eles que justificam a exigência da certidão, pois para este grupo a CND representa uma garantia de acesso às compras governamentais, que têm peso relevante nas suas receitas. Para aqueles com percentual de cumprimento acima de $100 \%$ os lucros estão garantidos, mesmo pagando integralmente os tributos devidos para retirar a CND. Estes lucros podem aumentar ainda mais caso o governo conceda a certidão sem observar cuidadosamente a regularidade fiscal da empresa. Neste grupo, a certidão tem um valor muito importante para seus negócios e quanto menos exigente for 0 governo na observância do cumprimento da obrigação tributária, maiores serão os lucros. São, portanto, para eles, que a Administração Tributária tem que prestar especial atenção, mesmo ao custo de redução da celeridade na emissão da certidão.

Em relação à Tabela 1, uma primeira observação é que há grande concentração de setores voltados para a construção civil, produtos farmacêuticos e principalmente serviços. Todos os sete setores considerados de maior risco estão neste grupo.

Os cinco setores com maior percentual são aqueles cuja proporção consumo público pelo consumo total são mais elevadas, atingindo $26 \%$ no caso de produtos farmacêuticos, ou seja, são setores muito dependentes das compras governamentais. Os quatros primeiros contam com alíquotas tributárias entre $9 \%$ e $11 \%$, ver apêndice, abaixo da média nacional $(12,3 \%)$ o que contribui para aumentar $0 \bar{\alpha}_{i}$. Os produtos farmacêuticos, por outro lado, são um caso à parte: são relativamente muito tributados, $\tau_{i}=21,7 \%$, o que atua no sentido de se reduzir 0 percentual para obtenção da CND. Entretanto, o fator peso do consumo público 
torna-se mais relevante e leva este setor a apresentar um $\bar{\alpha}_{i}$ elevado.

Também é interessante observar o que ocorreu com 0 setor de Serviços de Manutenção e Reparação, considerado de risco alto. A participação das compras do governo no faturamento é muito baixa, próxima de $3 \%$, mas por outro lado, a tributação também é baixa, cerca de 4,5\%. $\mathrm{Na}$ combinação dos dois fatores pesa mais a tributação reduzida, o que leva o setor a ter um percentual para a emissão da CND alto. 0 mesmo processo ocorre com o setor de Construção Civil, onde a participação do governo está muito próxima da média nacional, $6 \%$ contra $5 \%$, mas como a tributação é de apenas 5,9\%, muito inferior à média brasileira, este último fator acaba se sobrepondo, elevando o $\bar{\alpha}_{i}$.

Outro setor cuja análise é interessante é o de Serviços de Informação, onde o governo tem um peso relevante, $13 \%$, mas no qual a tributação também é elevada, $\tau_{i}=21,1 \%$. Considerando que cada um destes fatores atua em direções opostas, as duas forças se contrabalançam e 0 setor mostra um $\bar{\alpha}_{i}$ médio.

Finalmente, ressaltamos 0 setor de Produtos de Metal - Exclusive Máquinas e Equipamentos, no qual a tributação de $12,6 \%$ é praticamente idêntica à média nacional, mas que o peso do governo nas receitas é muito baixo, inferior a $2 \%, 0$ que reduz substancialmente 0 percentual mínimo requerido para a emissão da CND.

Por outro lado, para boa parte dos setores ter ou não a CND pode não ter muita importância para seus lucros. São setores nos quais o consumo do setor público não é relevante para 0 faturamento ou que a tributação seja relativamente mais elevada. $\mathrm{Na}$ maioria dos casos o primeiro fator é determinante, ou seja, trata-se de setores que não têm o governo como um cliente expressivo.

Tabela 1 - Resultados - Maiores Percentuais

\begin{tabular}{c|c|c}
\hline Setor Econômico & Percentual & Risco \\
\hline Serviços Prestados às Empresas & $214 \%$ & Alto \\
\hline Saúde Mercantil & $207 \%$ & Alto \\
\hline Tintas, vernizes, esmaltes e lacas & $157 \%$ & Alto \\
\hline Intermediação financeira e seguros & $142 \%$ & Alto \\
\hline Produtos farmacêuticos & $137 \%$ & Alto \\
\hline Construção & $126 \%$ & Alto \\
\hline Serviços de manutenção e reparação & $79 \%$ & Alto \\
\hline Serviços de informação & $69 \%$ & Médio \\
\hline Jornais, revistas e discos & $67 \%$ & Médio \\
\hline Produtos e preparados químicos diversos & $64 \%$ & Médio \\
\hline Álcool & $56 \%$ & Médio \\
\hline Serviços de alojamento e alimentação & $52 \%$ & Médio \\
\hline Média BRASIL & $43 \%$ & Médio \\
\hline Móveis e produtos das indústrias diversas & $37 \%$ & Médio \\
\hline Eletricidade e gás, água, esgoto e limpeza urbana & $34 \%$ & Médio \\
\hline Produtos químicos & $34 \%$ & Médio \\
\hline Produtos de metal - exclusive máquinas e equipamentos & $29 \%$ & Médio \\
\hline Fo
\end{tabular}

Fonte: Elaboração do autor. 
Tabela 2 - Resultados - Menores Percentuais

\begin{tabular}{|c|c|c|}
\hline Setor Econômico & Percentual & Risco \\
\hline Refino de petróleo e coque & $27 \%$ & Baixo \\
\hline Aparelhos/instrumentos médico-hospitalar, medida e óptico & $24 \%$ & Baixo \\
\hline Celulose e produtos de papel & $24 \%$ & baixo \\
\hline Educação mercantil & $24 \%$ & Baixo \\
\hline Transporte, armazenagem e correios & $20 \%$ & Baixo \\
\hline Alimentos & $16 \%$ & Baixo \\
\hline Outros produtos de minerais não-metálicos & $14 \%$ & Baixo \\
\hline Outros Serviços & $10 \%$ & Baixo \\
\hline Máquinas para escritório e equipamentos de informática & $9 \%$ & Baixo \\
\hline Máquinas, aparelhos e materiais elétricos & $5 \%$ & Baixo \\
\hline Outros equipamentos de transporte & $5 \%$ & Baixo \\
\hline Outros da indústria extrativa & $4 \%$ & Baixo \\
\hline Agricultura, silvicultura, exploração florestal & $4 \%$ & Baixo \\
\hline Produtos de madeira - exclusive móveis & $3 \%$ & Baixo \\
\hline Artigos do vestuário e acessórios & $3 \%$ & Baixo \\
\hline Peças e acessórios para veículos automotores & $2 \%$ & Baixo \\
\hline Perfumaria, higiene e limpeza & $2 \%$ & Baixo \\
\hline Artigos de borracha e plástico & $2 \%$ & Baixo \\
\hline Pecuária e pesca & $1 \%$ & Baixo \\
\hline Máquinas e equipamentos, inclusive manutenção e reparos & $1 \%$ & Baixo \\
\hline Têxteis & $1 \%$ & Baixo \\
\hline Metalurgia de metais não-ferrosos & $1 \%$ & Baixo \\
\hline Material eletrônico e equipamentos de comunicações & $1 \%$ & Baixo \\
\hline Artefatos de couro e calçados & $0 \%$ & Baixo \\
\hline Petróleo e gás natural & $0 \%$ & Baixo \\
\hline Minério de ferro & $0 \%$ & Baixo \\
\hline Produtos do fumo & $0 \%$ & Baixo \\
\hline Fabricação de resina e elastômeros & $0 \%$ & Baixo \\
\hline Defensivos agrícolas & $0 \%$ & Baixo \\
\hline Cimento & $0 \%$ & Baixo \\
\hline Fabricação de aço e derivados & $0 \%$ & Baixo \\
\hline Eletrodomésticos & $0 \%$ & Baixo \\
\hline Automóveis, camionetes e utilitários & $0 \%$ & Baixo \\
\hline Caminhões e ônibus & $0 \%$ & Baixo \\
\hline
\end{tabular}

Fonte: Elaboração do autor.

A Tabela 2 a seguir apresenta os setores considerados de baixo risco, ou seja, aqueles cujas exigências para o fornecimento da Certidão Negativa de Débito podem ser mais flexíveis. Há de se ressaltar a grande presença dos setores industriais e agrícolas, principalmente, ao contrário do que foi visto na Tabela 1, onde a concentração era maior no setor de serviços e construção civil.

Para este grupo de setores, a CND tem menor relevância, principalmente porque 0 setor público, de acordo com os dados nas contas nacionais do IBGE em 2006, não representa um mercado interessante para estas firmas. Assim, este grupo representa um risco menor para a Administração Pública.

Entretanto, os setores Refino de Petróleo e Coque e Aparelhos/instrumentos Médicohospitalares, Medida e Ótico possuem peso das compras de governo, $4 \%$ da receita, superior ao apresentado por alguns setores da Tabela 1, como Serviços de Manutenção e Reparação e Produtos Químicos. Refino de Petróleo e Aparelhos Médicos aparecem como 
de baixo risco por conta da tributação, que é bastante superior a dos dois setores citados na Tabela 1. A tributação atinge $16,9 \%$, bem maior do que a média nacional, o que contribui para colocar estes setores como de baixo risco para a emissão da CND.

Por fim, todos os setores nos quais o $\bar{\alpha}_{i}$ foi inferior a $4 \%$ na tabela 2 , praticamente não tem o governo entre seus clientes, ou seja, a participação das compras governamentais no faturamento é zero ou muito próximo disso, o que garante um baixo percentual, independe do que ocorra na tributação. Dentro deste grupo, temos setores com alíquotas expressivas, como é o caso da Perfumaria, Higiene e Limpeza, com $\tau_{i}=25,8 \%$, Produtos do Fumo, $\tau_{i}=37,5 \%$ e Eletrodomésticos cujo $\tau_{i}=40,9 \%$. O efeito da tributação é completamente anulado pela ausência do consumo público nestes setores.

\section{CONCLUSÕES}

Este artigo, através de um modelo simples de equilíbrio parcial, procurou analisar o efeito da Certidão Negativa de Débito sobre a decisão das firmas de pagar ou não tributos. Como foi mostrado, a falta da CND traz uma série de restrições para as firmas, como, por exemplo, participar de licitação pública, alienar ou onerar bem ou direito relativo a imóvel, a certidão é condição para 0 registro ou arquivamento de ato relativo à baixa ou redução de capital de firma individual, para redução de capital social, cisão total ou parcial, transformação ou extinção de entidade ou sociedade comercial ou civil e transferência de controle de cotas de sociedades de responsabilidade limitada, assim como também é condição para o reconhecimento de benefício ou incentivo fiscal e para a concessão de concordata e declaração de extinção das obrigações do falido.

Porém, este trabalho concentrou-se apenas na questão das compras públicas. Nesse sentido, as firmas escolhiam o quanto pagar de tributos, tendo em vista a possibilidade de fornecimento de bens e serviços ao setor público. As firmas escolhiam entre ser do tipo $L$, que não pagam tributos e não têm acesso ao consumo do setor público, ou ser do tipo $\mathrm{H}$, pagando o mínimo exigido pelo governo para concessão da CND, mas com acesso ao relevante mercado de compras governamentais.

Verificou-se que quanto mais tributado for o setor e/ou menor for a exposição do seu faturamento ao setor público menores deveriam ser as exigências do governo para concessão da CND. Há de se realçar que para alíquotas mais altas, o governo torna-se mais flexível porque a tributação mais elevada reduz o lucro das firmas e se o governo pretende que as firmas escolham ser do tipo $\mathrm{H}$ e não do $\mathrm{L}$, que não pagam tributos, então é obrigado a aceitar emitir a CND com menores exigências.

Com base na solução do modelo e em dados das contas nacionais de 2006, foram identificados os setores em que o governo deveria ser mais exigente na emissão da certidão, já que ela representa uma fonte importante de lucros. Entre estes setores estão os serviços prestados às empresas, construção civil, produtos farmacêuticos e serviços de informação. Por outro lado, foram apresentados os setores menos afetados pela CND, ou seja, firmas que não dependem ou dependem muito pouco das compras do governo. Entre elas, estão as empresas de eletrodomésticos, fumo, mineração e metalurgia.

A identificação dos setores mais afetados pela CND é importante, pois 0 governo deve atuar de forma mais rígida na concessão da certidão. Para este grupo de setores a CND é um passaporte importante para maiores lucros e quanto mais barato ela custar para ser obtida, melhor serão os resultados.

Finalmente, é preciso lembrar que a emissão da CND pode ser feita rapidamente pela internet nos casos em que não há pendências tributárias em torno do contribuinte. Por outro lado, quando há tais pendências, 0 processo de concessão pode se tornar extremamente lento e burocrático, trazendo custos que podem ser relevantes no caso de empresas que participem ativamente de compras do setor público. É preciso que a administração tributária esteja atenta e seja um 
agente facilitador de negócios e promotor do crescimento para aqueles contribuintes que procuram operar na legalidade. A certidão não pode se tornar um mecanismo que atravanque a economia dos que seguem a lei, mas sim um incentivo importante para que todos cumpram com suas obrigações tributárias.

\section{REFERÊNCIAS}

ALLINGHAM, M.G.; SANDMO, A. Income tax evasion: a theoretical analysis. Journal of Public Economics, [S. I.], v.1, p.323-338, 1972.

ARANTE, A. O. Reforma tributária, evasão fiscal e comportamento das firmas: um ensaio teórico sobre reações a cenários oriundos das Propostas de Emendas Constitucionais 285/2004 e 293/2004. 2006. Dissertação (Mestrado em Administração) Programa de Pós-Graduação em Administração, Universidade Federal de Pernambuco, Recife, 2006.

BRASIL. Ministério da Fazenda. Secretaria da Receita Federal do Brasil. Relatório de arrecadação 2006. Brasília, DF, 2007.

Presidência da República. Lei $\mathrm{n}$. 5.172 , de 25 de outubro de 1966. Dispõe sobre - Sistema Tributário Nacional e institui normas gerais de direito tributário aplicáveis à União, Estados e Municípios. Diário Oficial da União, Brasília, DF, 1966.

INSTITUTO BRASILEIRO DE GEOGRAFIA E ESTATÍSTICA. Sistema de contas nacionais 2002-2006. Rio de Janeiro, 2008.

MARRELLI, M. On indirect tax evasion. Journal of Public Economics, [S. I.], v. 25 p.181-196, 1984.

PRICEWATERHOUSECOOPERS

CONTADORES PÚBLICOS LTDA. Processo de obtenção de certidões negativas e os impactos na atividade empresarial brasileira. São Paulo, 2006.

SIQUEIRA, M.L.; RAMOS, F. S. Evasão Fiscal do imposto sobre a renda: Uma análise do comportamento do contribuinte ante o sistema impositivo brasileiro. Economia Aplicada, Ribeirão Preto, SP, v.10, p. 399-424, 2006.

YANIV, G. A note on tax evading firm. National Tax Journal, Washington, DC, v. 48 p. 113120, 1995.

NOTAS

1 Segundo a legislação tributária, Lei 9.430/96, a multa aplicada no lançamento de ofício é de $751 \%$ do montante devido, agravada para $1501 \%$ em caso de dolo, fraude ou simulação.

2 Informação retirada do site do Ministério da Fazenda. Disponível

em:<http://www.receita.fazenda.gov.br/srf/ResultFiscali zacao.htm>. Acesso em: 5 abr. 2009.

3 Total de impostos sobre a produção e 0 valor adicionado

${ }^{4}$ Alíquota - resultado da divisão dos impostos pela oferta - equivale ao $\tau_{i}$

${ }^{5}$ Consumo do governo - soma do consumo intermediário de bens e serviços pelos setores Saúde Pública, Educação pública e Serviço público e seguridade social e a demanda final da Administração Pública.

\section{Nelson Leitão Paes}

Engenheiro Mecatrônico

Doutor em Economia pela Universidade de Brasília

(UnB)

Professor da Pós-Graduação em Economia da

Universidade Federal de Pernambuco (UFPE)

E-mail: nlpaes@gmail.com

Universidade Federal de Pernambuco - UFPE

Av. Prof. Moraes Rego, 1235 - Cidade Universitária, Recife/PE

CEP: 50670-901 
APÊNDICE - CONTAS NACIONAIS 2006

\begin{tabular}{|c|c|c|c|c|c|}
\hline Setor Econômico & $\begin{array}{l}\text { Oferta Total a Preços } \\
\text { do Consumidor }\end{array}$ & Impostos $^{3}$ & Alíquota 4 & $\begin{array}{l}\text { Consumo } \\
\text { Governo } 5\end{array}$ & $\begin{array}{c}\text { Consumo } \\
\text { Privado }\end{array}$ \\
\hline $\begin{array}{l}\text { Agricultura, silvicultura, } \\
\text { exploração florestal. }\end{array}$ & 129.475 & 11.047 & $8,5 \%$ & 340 & 123.962 \\
\hline Pecuária e pesca & 68.212 & 9.633 & $14,1 \%$ & 114 & 67.849 \\
\hline Petróleo e gás natural & 107.811 & 3.239 & $3,0 \%$ & 0 & 85.244 \\
\hline Minério de ferro & 25.664 & 1.433 & $5,6 \%$ & 0 & 25.664 \\
\hline $\begin{array}{l}\text { Outros da indústria } \\
\text { extrativa }\end{array}$ & 28.141 & 1.838 & $6,5 \%$ & 41 & 18.248 \\
\hline Alimentos & 317.233 & 42.037 & $13,3 \%$ & 5.863 & 304.109 \\
\hline Produtos do fumo & 19.216 & 7.199 & $37,5 \%$ & 0 & 16.958 \\
\hline Têxteis & 41.085 & 4.248 & $10,3 \%$ & 26 & 38.136 \\
\hline $\begin{array}{l}\text { Artigos do vestuário e } \\
\text { acessórios }\end{array}$ & 34.354 & 4.870 & $14,2 \%$ & 123 & 33.417 \\
\hline $\begin{array}{c}\text { Artefatos de couro e } \\
\text { calçados }\end{array}$ & 27.310 & 4.422 & $16,2 \%$ & 1 & 26.388 \\
\hline $\begin{array}{l}\text { Produtos de madeira - } \\
\text { exclusive móveis }\end{array}$ & 21.645 & 2.176 & $10,1 \%$ & 65 & 21.289 \\
\hline $\begin{array}{c}\text { Celulose e produtos de } \\
\text { papel }\end{array}$ & 45.355 & 6.072 & $13,4 \%$ & 1.199 & 41.216 \\
\hline Jornais, revistas, discos. & 34.600 & 3.982 & $11,5 \%$ & 2.272 & 31.349 \\
\hline $\begin{array}{l}\text { Refino de petróleo e } \\
\text { coque }\end{array}$ & 178.295 & 30.101 & $16,9 \%$ & 6.665 & 156.227 \\
\hline Álcool & 20.804 & 1.920 & $9,2 \%$ & 931 & 19.625 \\
\hline Produtos químicos & 74.710 & 4.282 & $5,7 \%$ & 994 & 57.935 \\
\hline $\begin{array}{c}\text { Fabricação de resina e } \\
\text { elastômeros }\end{array}$ & 36.212 & 2.215 & $6,1 \%$ & 0 & 29.119 \\
\hline Produtos farmacêuticos & 46.966 & 10.181 & $21,7 \%$ & 10.009 & 25.718 \\
\hline Defensivos agrícolas & 13.030 & 1.670 & $12,8 \%$ & 0 & 11.270 \\
\hline $\begin{array}{c}\text { Perfumaria, higiene e } \\
\text { limpeza. }\end{array}$ & 30.714 & 7.915 & $25,8 \%$ & 118 & 26.729 \\
\hline $\begin{array}{c}\text { Tintas, vernizes, esmaltes } \\
\text { e lacas. }\end{array}$ & 10.068 & 1.050 & $10,4 \%$ & 1.357 & 7.857 \\
\hline $\begin{array}{l}\text { Produtos e preparados } \\
\text { químicos diversos }\end{array}$ & 18.076 & 2.061 & $11,4 \%$ & 940 & 13.638 \\
\hline $\begin{array}{l}\text { Artigos de borracha e } \\
\text { plástico }\end{array}$ & 57.761 & 6.220 & $10,8 \%$ & 82 & 52.495 \\
\hline Cimento & 9.062 & 1.459 & $16,1 \%$ & 0 & 9.014 \\
\hline $\begin{array}{l}\text { Outros produtos de } \\
\text { minerais não-metálicos }\end{array}$ & 34.737 & 4.556 & $13,1 \%$ & 515 & 32.558 \\
\hline $\begin{array}{c}\text { Fabricação de aço e } \\
\text { derivados }\end{array}$ & 75.833 & 5.444 & $7,2 \%$ & 0 & 71.653 \\
\hline $\begin{array}{l}\text { Metalurgia de metais não- } \\
\text { ferrosos }\end{array}$ & 39.529 & 2.577 & $6,5 \%$ & 12 & 33.023 \\
\hline $\begin{array}{l}\text { Produtos de metal - } \\
\text { exclusive máquinas e } \\
\text { equipamentos }\end{array}$ & 64.266 & 8.112 & $12,6 \%$ & 1.932 & 58.178 \\
\hline Máquinas e & 99.370 & 15.727 & $15,8 \%$ & 99 & 79.639 \\
\hline
\end{tabular}




\begin{tabular}{|c|c|c|c|c|c|}
\hline $\begin{array}{c}\text { equipamentos, inclusive } \\
\text { manutenção e reparos. }\end{array}$ & 18.091 & 7.404 & $40,9 \%$ & 0 & 17.497 \\
\hline $\begin{array}{c}\text { Eletrodomésticos } \\
\begin{array}{c}\text { Máquinas para escritório } \\
\text { e equipamentos de } \\
\text { informática }\end{array}\end{array}$ & 26.784 & 3.633 & $13,6 \%$ & 211 & 19.462 \\
\hline $\begin{array}{c}\text { Máquinas, aparelhos e } \\
\text { materiais elétricos. }\end{array}$ & 48.882 & 6.846 & $14,0 \%$ & 242 & 40.927 \\
\hline $\begin{array}{c}\text { Material eletrônico e } \\
\text { equipamentos de } \\
\text { comunicações }\end{array}$ & 63.570 & 8.503 & $13,4 \%$ & 18 & 42.926 \\
\hline $\begin{array}{c}\text { Aparelhos/instrumentos } \\
\text { médico-hospitalar, } \\
\text { medida e óptico. }\end{array}$ & 24.221 & 4.102 & $16,9 \%$ & 543 & 14.286 \\
\hline $\begin{array}{c}\text { Automóveis camionetes e } \\
\text { utilitários }\end{array}$ & 83.412 & 15.984 & $19,2 \%$ & 0 & 77.028 \\
\hline Caminhões e ônibus & 18.235 & 2.101 & $11,5 \%$ & 0 & 17.538 \\
\hline $\begin{array}{c}\text { Peças e acessórios para } \\
\text { veículos automotores }\end{array}$ & 65.720 & 7.076 & $10,8 \%$ & 117 & 57.542 \\
\hline $\begin{array}{c}\text { Outros equipamentos de } \\
\text { transporte }\end{array}$ & 36.562 & 3.131 & $8,6 \%$ & 103 & 29.481 \\
\hline $\begin{array}{c}\text { Móveis e produtos das } \\
\text { indústrias diversas }\end{array}$ & 43.837 & 8.528 & $19,5 \%$ & 2.678 & 38.925 \\
\hline $\begin{array}{c}\text { Eletricidade e gás, água, } \\
\text { esgoto e limpeza urbana. }\end{array}$ & 179.572 & 36.572 & $20,4 \%$ & 10.805 & 163.264 \\
\hline
\end{tabular}

Fonte: IBGE (2008). 